\section{THE FUTURE OF GALL-STONES PATIENTS.} GUSTAVE MONOD, M.D., M.R.C.P.,

M. ROUZAUD, M.D., PHYSICIANS AT VICHY.

Trr localization of stones in the gall bladder and the surgical problem it often poses have dominated for a long time the whole history of biliary lithiasis. Until recent times the classical treatises dealt almost exclusively with the calculus, its migrations, its dangers, its local complications, and the ultimate effect on the liver. Murchison, however, was one of the first to note the frequent relationship, either immediate or remote, of gall stones with certain lesions, and with certain alterations in the tissues and viscera, in particular with gouty nephritis.

In explaining biliary lithiasis by a hypothesis of hypercholesterinaemia, Professor Chauffard enlarged the limits of the subject. From a purely hepatic disease biliary lithiasis has become a very much more general one. We can even detect its presence before the painful crises, and we can follow its insidious progress after they have disappeared. In the light of this new knowledge the role of the liver loses nothing of its importance. Without waiting for the formation or the migration of the calculi, we are in a position to appreciate the defect of the liver, whether it be congenital or acquired, which is at the bottom of the lithiatic tendency and which controls the local or general phenomena.

After having systematically followed, since 1912, the basic disorder underlying cases of biliary lithiasis, we have adopted in this research work the scheme of examination published by one of us, and which consists in (a) the study of viscosity of the blood by the method of Hess, and of the blood pressure by Pachon's oscillometer; (b) the estimation in the blood of biliary pigments, of cholesterin, of urea, of residual nitrogen, of uric acid, and of glucose; (c) the estimation of the ureo-secretory coefficient of Ambard.

During the course of this work we have relied solely on complete clinical and biochemical observations of patients in whom the diagnosis of gall stones was well proved, and have not availed ourselves of cases in which we had no opportunity of controlling our diagnosis by operation or $\boldsymbol{x}$ rays, or the actual passage of calculi.

Of the ninety cases under observation, six underwent complete examinations at long intervals-in one case the interval amounted to nine years, by which time the clinical picture was completely modified; the others were sern either at the actual onset of their trouble or else very much later. As a result of being able to follow up the same patient, or different patients, it appeared to us that it would be possible to trace the complete pathological progress of this diseaseprogress followed more or less rapidly by the majority of our patients.

Whilst the troubles are primarily of hepatic or humoral origin they become generalized slowly, insidiously throughout the whole body, presenting eventually a clinical picture which may seem to have little or no connexion with the liver. The rare exception to this rulo occurs in cases in which the biliary colic was incidental, following a sudden simple rise in the blood content of cholesterol. Such a crisis constitutes the whole course of the disease. Predisposition is, we may say, necessary: "Ne fait pas de la lithiase qui veut."

For purposes of convenience we have divided these ninety cases into four groups to represent four main points of a curve. Actually each type of case may follow its course more or less rapidly. Some patients may remain perpetually in statu quo.

\section{First Group. (See Table I.)}

The characteristics of the patients in this group, who are young (20 to 40 ) and present a clinical picture of acute or subacute biliary colic, are the following:

(a) The viscosity of the blood is normal or slightly increased.

(b) The arterial pressure is normal.

(c) Cholaemia is constant, but rather low, if we except those cases which are accompanied by a retention of bile due to calculi.

(d) Cholesterinaemia is increased, but rarely rises above 2.10, except in cases of complete biliary obstruction. In certain cases, however, it is not rare to find cholesterinaemia which is normal, or only slightly raised, after a crisis terminating in the expulsion of biliary slime or calculi, as if such a crisis represented an effort towards the elimination of cholesterol from the system. In a previous work we have cited six cases of this nature, which we may compare with cases of renal calculus in which hyperuricaemia is controlled by an abundant elimination of uric acid.

(e) Protein metabolism is fairly normal, if we may judge by the output of urea and residual nitrogen. Uric acid, however, is almost invariably increased, and this early association between the increased amount of cholesterol and urio acid in the blood is, in our opinion, evidence of some hepatio derangement leading to lithiasis. This hyperuricaemia gives rise to no clinical symptoms, since the kidney function can be shown to be intact by estimating Ambard's coefficient of excretion-secretion.

$(f)$ Lastly, it is very frequent to find in these cases a slight increase in the blood sugar. Without doubt, in such an increase may be found the explanation of the fact that certain of these patients pass sugar or are liable to become diabetics.

To summarize, in this first stage towards lithiasis: so long as the clinical symptoms are purely liver symptoms, our biochemical examinations seem to prove that the trouble is rather biliary than hepatic, since the liver cell retains its activity and the cardiac and renal apparatus are unaffected. From this point patients may take either of two routes: some, the exception, remain subacute or chronic stone cases, the gall-bladder symptoms remaining pre-eminent and sometimes exclusive; these will be found in the second group. The others (the majority) cease to be purely hepatic cases; they tend towards complications of a more general character and will be found in the third group.

\section{Second Group. (See Table II.)}

In these cases the viscosity of the blood is raised and the arterial pressure is found to be variable. It is not uncommon to find dilatation of the right heart. Cholaemia is raised without a parallel increase in cholesterinaemia. Such a dissociation shows the cells of the liver to be affected-a fact which is further evidenced by the marked increase of the residual nitrogen, of the uric acid in the blood, and of the ammonia content of the urine. The blood sugar remains slightly raised. The ureo-secretory coefficient goes somewhat up without an increase of the blood urea, and the urea concentration of the urine shows no deficiency of the kidneys.

Clinically we easily recognize this type of patient with active congestion of the liver and the resulting symptoms of portal engorgement. This defensive active congestion, by means of which hypercholesterinaemia is controlled, eventually hampers the general circulation, and, the right heart giving way, a secondary and passive congestion ensues. Under the influence of these repeated stages of congestion the liver cells gradually lose their activity, and biliary cirrhosis, especially of tho left lobe, becomes the predominating feature. In these cases the renal and cardiac troubles maintain an obvious connexion with those of the liver. But more often these patients, as time goes on, suffer less: they have, perhaps, eliminated several calculi; they do not complain of their liver, and their general state improves.

\section{Third Group. (See Table III.)}

In these cases the following characteristics may be noted. Viscosity is increased, and this concentration of the blood can be explained by increased diuresis, which is the means adopted by the already damaged kidney to prevent an accumulation of toxic products. The uric acid concentration of the urine is gradually lowered from 15 to 12 or even 10 grams per litre, and the coefficient of Ambard may rise above 0.1 , indicating a reduction of from a third to a half of the renal function. The arterial pressure is markedly raised, especially in the diastolic phase, but generally, owing to the raised systolic and hypertrophy of the heart, the circulatory compensation is adequately maintained. These are exactly the characteristics which Martinet described as pre-sclerotic. 


\begin{tabular}{|c|c|c|c|c|c|c|c|c|c|c|c|c|}
\hline $\begin{array}{l}\text { Case } \\
\text { No. }\end{array}$ & Age. & Sex. & Viscosity. & Blood I & ressure. & $\begin{array}{c}\text { Bile } \\
\text { Pigments. }\end{array}$ & $\begin{array}{l}\text { Cholesterin } \\
\text { in Serum. }\end{array}$ & $\begin{array}{l}\text { Urea in } \\
\text { Serum. }\end{array}$ & $\begin{array}{l}\text { Residual } \\
\text { Nitrogen. }\end{array}$ & Uric Acid & Sugar. & $\begin{array}{c}\text { Ureo- } \\
\text { secretory } \\
\text { Coefficient. }\end{array}$ \\
\hline $\begin{array}{c}1 \\
2 \\
3 \\
4 \\
4 \\
5 \\
6 \\
7 \\
8 \\
9 \\
10 \\
11 \\
12^{*} \\
13 \\
14 \\
15 \\
16 \\
17 \\
18 \\
19 \\
20 \\
21 \\
22 \\
23 \\
24 \\
25 \\
26 \\
\end{array}$ & $\begin{array}{l}31 \\
29 \\
39 \\
34 \\
28 \\
37 \\
39 \\
29 \\
31 \\
34 \\
29 \\
36 \\
27 \\
21 \\
24 \\
31 \\
44 \\
33 \\
28 \\
26 \\
30 \\
31 \\
31 \\
29 \\
27 \\
39\end{array}$ & 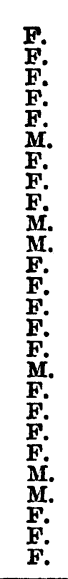 & $\begin{array}{l}5.1 \\
5.1 \\
4.5 \\
4.8 \\
4.4 \\
5.1 \\
4.9 \\
4.5 \\
4.9 \\
5.4 \\
4.9 \\
4.2 \\
4.4 \\
4.2 \\
4.5 \\
5.2 \\
4.7 \\
4.4 \\
4.4 \\
4.6 \\
4.3 \\
4.6 \\
5.4 \\
4.4 \\
5.1 \\
4.7\end{array}$ & $\begin{array}{c}\text { Systolio. } \\
13.5 \\
14.0 \\
17.0 \\
16.0 \\
13.0 \\
15.0 \\
12.0 \\
19.0 \\
13.0 \\
13.0 \\
12.5 \\
13.0 \\
14.0 \\
14.0 \\
15.0 \\
16.0 \\
14.0 \\
11.0 \\
12.5 \\
13.0 \\
15.0 \\
13.0 \\
15.0 \\
14.0 \\
14.0\end{array}$ & $\begin{array}{r}\text { Diastolic. } \\
9.5 \\
9.5 \\
10.0 \\
10.0 \\
8.5 \\
9.0 \\
8.5 \\
8.5 \\
11.0 \\
9.5 \\
8.0 \\
8.0 \\
9.0 \\
9.0 \\
8.5 \\
10.0 \\
9.0 \\
9.0 \\
8.0 \\
10.0 \\
9.0 \\
8.0 \\
9.0 \\
9.0 \\
9.5 \\
9.5\end{array}$ & $\begin{array}{l}1 / 25,000 \\
1 / 28000 \\
1 / 25,000 \\
1 / 26.000 \\
1 / 25,000 \\
1 / 18,000 \\
1 / 24,000 \\
1 / 24,000 \\
1 / 27.000 \\
1 / 24,000 \\
1 / 28,000 \\
1 / 30,000 \\
1 / 24,000 \\
1 / 28,000 \\
1 / 24,000 \\
1 / 28,000 \\
1 / 24,000 \\
1 / 27,000 \\
1 / 27,000 \\
1 / 26,000 \\
1 / 30,000 \\
1 / 30,000 \\
1 / 29,000 \\
1126,000 \\
1 / 28,000 \\
1 / 25,000\end{array}$ & $\begin{array}{l}2.13 \\
2.19 \\
1.47 \\
2.02 \\
1.86 \\
2.27 \\
1.92 \\
2.43 \\
1.86 \\
1.89 \\
1.53 \\
1.80 \\
2.31 \\
2.08 \\
2.31 \\
.2 .34 \\
2.19 \\
1.77 \\
2.37 \\
2.01 \\
1.59 \\
1.86 \\
2.16 \\
1.86 \\
2.19 \\
2.04\end{array}$ & $\begin{array}{l}0.26 \\
0.27 \\
0.28 \\
0.47 \\
0.175 \\
0.23 \\
0.38 \\
0.37 \\
0.34 \\
0.24 \\
0.285 \\
0.182 \\
0.432 \\
0.305 \\
0.121 \\
0.235 \\
0.352 \\
0.183 \\
0.43 \\
0.293 \\
0.219 \\
0.262 \\
0.237 \\
0.27\end{array}$ & 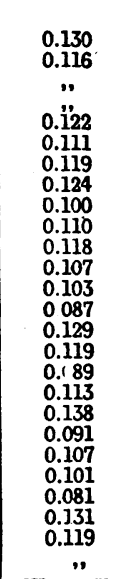 & $\begin{array}{l}0.061 \\
0.041 \\
0.045 \\
0.0050 \\
0.054 \\
0.059 \\
0.068 \\
\ddot{\#} \\
0.053 \\
0.049 \\
0.079 \\
0.074 \\
0.059 \\
0.052 \\
0.0059 \\
0.070 \\
0.042 \\
0.050 \\
0.059 \\
0.334 \\
0.063 \\
0.059 \\
0.049\end{array}$ & $\begin{array}{l}1.22 \\
1.26 \\
1.18 \\
1.27 \\
1.98 \\
1.29 \\
1.42 \\
1.33 \\
1.34 \\
1.41 \\
1.01 \\
1.18 \\
0.98 \\
1.27 \\
1.22 \\
1.98 \\
1.17 \\
1.33 \\
1.32 \\
1.48 \\
1.47 \\
1.26 \\
1.15\end{array}$ & $\begin{array}{l}0.063 \\
0 .(53 \\
0.080 \\
0.071 \\
0.066 \\
0.055 \\
0.069 \\
0.071 \\
0.077 \\
0.068 \\
0.074 \\
0.061 \\
0.066 \\
0.072 \\
0.082 \\
0.071 \\
0.087 \\
0.081 \\
0.072 \\
0.058 \\
0.075 \\
0.078 \\
0.060 \\
0.073 \\
0.053 \\
0.069\end{array}$ \\
\hline Mean: & & & 4.7 & 14.0 & 9.0 & $1 / 26,000$ & 2.01 & 0.26 & 0.112 & 0.059 & 1.26 & 0.069 \\
\hline
\end{tabular}

"First examination.

TABLE II (19 Observations).

\begin{tabular}{|c|c|c|c|c|c|c|c|c|c|c|c|c|}
\hline $\begin{array}{c}1 \\
2 \\
3 \\
4 \\
5 \\
6 \\
7 \\
8 \\
9 \\
10 \\
11 \\
12 \\
13 \\
14 \\
15 \\
16 \\
17 \\
18 \\
19^{*}\end{array}$ & $\begin{array}{l}37 \\
47 \\
46 \\
58 \\
51 \\
52 \\
47 \\
54 \\
36 \\
42 \\
39 \\
48 \\
53 \\
45 \\
51 \\
42 \\
54 \\
70 \\
72\end{array}$ & 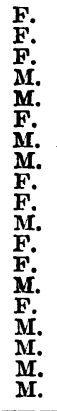 & $\begin{array}{l}4.8 \\
4.8 \\
5.9 \\
5.6 \\
5.4 \\
6.3 \\
7.8 \\
5.4 \\
5.2 \\
5.4 \\
5.0 \\
5.0 \\
5.8 \\
5.7 \\
5.8 \\
5.1 \\
6.2 \\
5.2 \\
5.8\end{array}$ & $\begin{array}{l}15.5 \\
15.0 \\
16.0 \\
19.0 \\
15.0 \\
18.0 \\
19.0 \\
15.0 \\
14.0 \\
17.0 \\
13.0 \\
16.0 \\
15.0 \\
16.0 \\
18.0 \\
16.0 \\
16.0 \\
18.0 \\
19.0\end{array}$ & $\begin{array}{r}10.0 \\
10.0 \\
10.0 \\
10.5 \\
10.0 \\
90.0 \\
10.0 \\
10.0 \\
9.5 \\
8.5 \\
8.5 \\
7.5 \\
10.0 \\
10.0 \\
9.5 \\
9.0 \\
8.0 \\
10.0 \\
10.5\end{array}$ & $\begin{array}{l}1 / 16.000 \\
1 / 20.000 \\
1 / 22,000 \\
1 / 24,000 \\
1 / 20.000 \\
1 / 22,000 \\
1 / 24,000 \\
1 / 25,000 \\
1 / 23,000 \\
1 / 22,000 \\
1 / 20,000 \\
1 / 23,000 \\
1 / 18.000 \\
1 / 22,000 \\
1 / 20,000 \\
1 / 25000 \\
1 / 16,000 \\
1 / 22,000 \\
1 / 20,000\end{array}$ & $\begin{array}{l}2.21 \\
2.04 \\
2.07 \\
2.17 \\
1.98 \\
2.01 \\
2.04 \\
2.28 \\
2.37 \\
1.89 \\
2.17 \\
1.56 \\
1.77 \\
2.01 \\
2.02 \\
1.95 \\
2.16 \\
2.16 \\
1.92\end{array}$ & $\begin{array}{l}0.28 \\
0 . \ddot{2} 7 \\
0.29 \\
0.26 \\
0.33 \\
0.28 \\
0.32 \\
0.36 \\
0.25 \\
0.36 \\
0.36 \\
0.23 \\
0.48 \\
0.34 \\
0.29 \\
0.41 \\
0.25 \\
0.36\end{array}$ & $\begin{array}{l}0.141 \\
0 . \ddot{4} 49 \\
0.186 \\
0.128 \\
0.147 \\
0.139 \\
0.163 \\
0.145 \\
0.135 \\
0.147 \\
0.160 \\
0.152 \\
0.169 \\
0.134 \\
0.138 \\
0.163 \\
0.179 \\
0.167\end{array}$ & 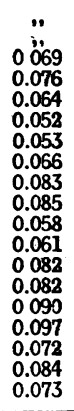 & $\begin{array}{l}1.14 \\
1.36 \\
1.28 \\
1.03 \\
1.22 \\
1.39 \\
1.01 \\
1.06 \\
1.33 \\
1.07 \\
1.16 \\
1.02 \\
1.16 \\
1.42 \\
1.38 \\
1.28 \\
1.26\end{array}$ & $\begin{array}{l}0.076 \\
0.070 \\
0.088 \\
0.092 \\
0.076 \\
0.096 \\
0.086 \\
0.084 \\
0.082 \\
0.090 \\
0.079 \\
0.092 \\
0.081 \\
0.091 \\
0.080 \\
0.069 \\
0.087 \\
0.085 \\
0.097\end{array}$ \\
\hline Mean: & & & 5.6 & 16.0 & 10.0 & $1 / 21,000$ & 2.03 & 0.32 & 0.152 & 0.073 & 1.20 & 0.084 \\
\hline
\end{tabular}

${ }^{*}$ Same case as No. 18.

TABLE III (27 Observations).

\begin{tabular}{|c|c|c|c|c|c|c|c|c|c|c|c|c|}
\hline $\begin{array}{c}1 \\
2 \\
3 \\
4 \\
5 \\
6 \\
7^{*} \\
8 \\
9^{*} \\
10^{*} \\
11 \\
12 \\
13 \\
14 \\
15 \\
16 \\
17 \\
18 \\
19^{*} \\
20 \\
21 \\
22 \\
23+ \\
24 \\
25 \\
26 \\
27\end{array}$ & $\begin{array}{l}54 \\
53 \\
49 \\
54 \\
45 \\
51 \\
52 \\
43 \\
59 \\
41 \\
50 \\
61 \\
55 \\
48 \\
47 \\
51 \\
43 \\
56 \\
51 \\
60 \\
46 \\
37 \\
51 \\
57 \\
53 \\
42 \\
58\end{array}$ & 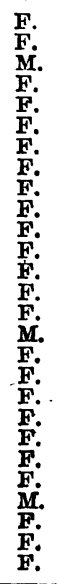 & $\begin{array}{l}6.4 \\
5.3 \\
6.5 \\
7.2 \\
5.2 \\
6.8 \\
5.7 \\
5.8 \\
7.2 \\
4.9 \\
5.6 \\
5.2 \\
5.0 \\
5.1 \\
5.8 \\
6.1 \\
5.4 \\
5.9 \\
4.6 \\
5.2 \\
6.3 \\
5.6 \\
5.0 \\
5.8 \\
4.8 \\
5.1 \\
6.2\end{array}$ & $\begin{array}{l}19.0 \\
18.0 \\
22.5 \\
25.0 \\
21.5 \\
18.5 \\
18.0 \\
22.0 \\
23.0 \\
15.0 \\
16.0 \\
15.0 \\
21.5 \\
18.0 \\
22.0 \\
18.0 \\
21.5 \\
21.0 \\
23.0 \\
22.0 \\
18.0 \\
17.5 \\
22.0 \\
21.0 \\
18.0 \\
13.5 \\
19.0\end{array}$ & $\begin{array}{r}11.5 \\
9.0 \\
13.0 \\
14.0 \\
12.5 \\
12.0 \\
10.5 \\
12.0 \\
12.0 \\
10.0 \\
10.5 \\
9.5 \\
12.5 \\
12.0 \\
13.0 \\
10.0 \\
11.0 \\
11.0 \\
11.0 \\
11.0 \\
10.0 \\
10.5 \\
12.0 \\
11.5 \\
10.0 \\
10.0 \\
11.0\end{array}$ & 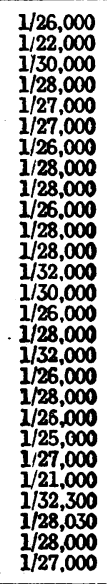 & $\begin{array}{l}2.49 \\
2.40 \\
2.40 \\
2.73 \\
2.64 \\
2.90 \\
3.42 \\
2.67 \\
2.28 \\
2.79 \\
2.65 \\
2.39 \\
2.21 \\
2.37 \\
2.22 \\
2.19 \\
2.35 \\
2.49 \\
3.55 \\
3.15 \\
2.76 \\
2.67 \\
2.61 \\
2.60 \\
2.67 \\
2.79 \\
3.69\end{array}$ & $\begin{array}{l}0.205 \\
0.43 \\
0.285 \\
0.285 \\
0.22 \\
0.29 \\
0.22 \\
0.38 \\
0.41 \\
0.31 \\
0.29 \\
0.37 \\
0.44 \\
0.47 \\
0.57 \\
0.45 \\
0.44 \\
0.37 \\
0.20 \\
0.30 \\
0.41 \\
0.31 \\
0.295 \\
0.31 \\
0.275 \\
0.36 \\
0.32\end{array}$ & $\begin{array}{l}0.138 \\
0.142 \\
0.149 \\
0.143 \\
0.157 \\
0.155 \\
0.121 \\
0.139 \\
0.177 \\
0.139 \\
0.131 \\
0.130 \\
0.136 \\
0.152 \\
0.148 \\
0.155 \\
0.156 \\
0.157 \\
0.141 \\
0.136 \\
0.148 \\
0129 \\
0.128 \\
0.107 \\
0.117 \\
0.144\end{array}$ & $\begin{array}{l}0.074 \\
0.078 \\
0.055 \\
0.061 \\
0.062 \\
0.061 \\
0.060 \\
0.064 \\
0.099 \\
0.068 \\
0.055 \\
0.052 \\
0.059 \\
0.048 \\
0.070 \\
0.072 \\
0.078 \\
0.066 \\
0.088 \\
0.067 \\
0.062 \\
0.059 \\
0.056 \\
0.046 \\
0.041 \\
0.051 \\
0.057\end{array}$ & $\begin{array}{l}1.29 \\
1.08 \\
1.22 \\
1.31 \\
1.07 \\
1.22 \\
1.18 \\
1.21 \\
1.47 \\
1.28 \\
1.12 \\
1.08 \\
1.10 \\
1.24 \\
0.96 \\
1.32 \\
1.10 \\
1.02 \\
1.47 \\
1.15 \\
122 \\
1.60 \\
1.60 \\
1.19 \\
1.21\end{array}$ & $\begin{array}{l}0.099 \\
0.101 \\
0.081 \\
0.084 \\
0.692 \\
0.107 \\
0.084 \\
0.099 \\
0.129 \\
0.089 \\
0.094 \\
0.106 \\
0.104 \\
0.097 \\
0.101 \\
0.093 \\
0.101 \\
0.102 \\
0.109 \\
0.103 \\
0.097 \\
0.085 \\
0.086 \\
0.093 \\
0.091 \\
0.080\end{array}$ \\
\hline Mean: & & & 6.8 & 20.0 & 21.0 & $1 / 29,000$ & 2.65 & 0.34 & 0.139 & 0.064 & 1.19 & 0.098 \\
\hline
\end{tabular}

* First examination. † Second examination.

TABLE IV (18 Observations).

\begin{tabular}{|c|c|c|c|c|c|c|c|c|c|c|c|c|}
\hline $\begin{array}{c}1^{*} \\
2^{*} \\
3 \\
4^{*} \\
5 \\
6 \\
7 \\
8 \\
9 \\
10 \\
11 \\
12 \\
13 \\
14^{*} \\
15 \\
16^{*} \\
17 \\
18\end{array}$ & $\begin{array}{l}52 \\
62 \\
53 \\
59 \\
62 \\
52 \\
58 \\
59 \\
62 \\
68 \\
66 \\
64 \\
68 \\
71 \\
67 \\
67 \\
61\end{array}$ & 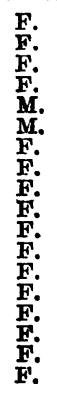 & $\begin{array}{l}4.4 \\
5.1 \\
4.4 \\
4.6 \\
4.4 \\
2.6 \\
3.9 \\
3.8 \\
4.9 \\
4.6 \\
4.1 \\
5.0 \\
4.4 \\
4.1 \\
3.4 \\
4.1 \\
4.1 \\
5.0\end{array}$ & $\begin{array}{l}20.0 \\
19.0 \\
15.5 \\
17.0 \\
17.0 \\
18.0 \\
15.0 \\
19.0 \\
17.0 \\
19.0 \\
18.0 \\
19.0 \\
15.0 \\
18.0 \\
200 \\
17.0 \\
20.0 \\
13.0\end{array}$ & $\begin{array}{r}11.5 \\
12.0 \\
10.0 \\
12.0 \\
11.0 \\
9.5 \\
10.5 \\
11.0 \\
11.0 \\
10.5 \\
11.0 \\
10.5 \\
8.5 \\
11.0 \\
11.0 \\
11.0 \\
11.5 \\
9.5\end{array}$ & $\begin{array}{l}1 / 28,000 \\
1 / 28,000 \\
1 / 26,000 \\
1 / 30,000 \\
1 / 28,000 \\
1 / 28,000 \\
1 / 28,000 \\
1 / 30,000 \\
1 / 26,000 \\
1 / 30.000 \\
1 / 29,000 \\
1 / 24,000 \\
1 / 24,000 \\
1 / 30,000 \\
1128,000 \\
1 / 27,000 \\
1330.000 \\
1 / 27,000\end{array}$ & $\begin{array}{l}2.73 \\
2.52 \\
2.88 \\
2.97 \\
2.76 \\
2.79 \\
3.10 \\
2.28 \\
3.15 \\
2.40 \\
2.37 \\
2.43 \\
2.64 \\
3.16 \\
2.44 \\
2.76 \\
2.43 \\
2.58\end{array}$ & $\begin{array}{l}0.54 \\
0.61 \\
0.44 \\
0.51 \\
0.53 \\
0.55 \\
0.43 \\
0.43 \\
0.54 \\
0.48 \\
0.58 \\
0.49 \\
0.49 \\
0.37 \\
0.54 \\
0.40 \\
0.43 \\
0.36\end{array}$ & $\begin{array}{l}0.169 \\
0.178 \\
0.142 \\
0.169 \\
0.139 \\
0.159 \\
0.193 \\
0.149 \\
0.12 \\
0.144 \\
0.157 \\
0.122 \\
0.147 \\
0.162 \\
0.176 \\
0.161 \\
0.153\end{array}$ & $\begin{array}{l}0.088 \\
0.097 \\
0.091 \\
0.087 \\
0.063 \\
0.081 \\
0.061 \\
0.088 \\
0.066 \\
0.072 \\
0.074 \\
0.072 \\
0.079 \\
0.077 \\
0.082 \\
0.088 \\
0.087\end{array}$ & $\begin{array}{l}1.22 \\
1.09 \\
1.16 \\
1.22 \\
1.37 \\
1.19 \\
1.16 \\
1.15 \\
1.26 \\
1.25 \\
1.19 \\
1.37 \\
1.07 \\
1.33 \\
1.28 \\
1.135 \\
1.27\end{array}$ & $\begin{array}{l}0.152 \\
0.149 \\
0.142 \\
0.136 \\
0.140 \\
0.177 \\
0.112 \\
0.140 \\
0.115 \\
0.118 \\
0.145 \\
0.120 \\
0.137 \\
0.154 \\
0.184 \\
0.149 \\
0.160 \\
0.132\end{array}$ \\
\hline Mean: & & & 4.2 & 17.0 & 11.0 & $1 / 28,000$ & 2.70 & 0.49 & 0.153 & 0.078 & 1.28 & 0.141 \\
\hline
\end{tabular}


Cholaemia is slightly, and cholesterinaemia is markedly, raised. This is the period at which chronic gall-bladder cases present local deposits of cholesterin. Chauffard has well shown that the system endeavours by all possible means to eliminate from the blood stream any excess of cholesterol.

Residual nitrogen and uric acid, less markedly increased than in the second group, are nevertheless above normal; the cells of the liver are less affected than in the latter group, but the deficiency of heart and kidney is more marked. It is the factor which will assume the supreme importance in the fourth group.

\section{Fourth Grovp. (See Table IV.)}

In this group heart failure sets in and the blood gets more and more diluted. Albuminuria appears at the same time. The urea concentration of the urine falls coincidentally and Ambard's coefficient, by its increase of value, shows a progressive degeneration of the kidney. Hypercholesterinaemia remains very high, as also does the nitrogen and uric acid content of the blood. In brief, the cases in this group present the humoral characteristics of Bright's disease. As a matter of fact, these results enable us to trace the connexion between lithiasis and the condition underlying Bright's disease, and tend to verify the hypothesis of Chabanier that such a nephritis is the final development of a general condition.

\section{Conclusions.}

From the preceding facts wo can draw the following therapeutical conclusions.

The gall-bladder localization must not be considered as the only guide to correct treatment. It can only be used to determine the need for surgical intervention. The essential treatment must be based on the conception of a general metabolic disorder, previous to calculus formation, in which the liver plays the predominant part. The safety-valve furnished by the biliary apparatus is of the utmost importance; it can act by preventing general and local complications.

Whilst therapeutic measures are practically ineffective once complications of the cardiac and renal systems are established (when symptomatic treatment is the best that is available), it is possible in the periods preceding painful or insidious lithiasis to amend and correct the function of the liver by more effective therapeutic measures than have previously been employed.

\section{TREATMENT OF SLEEPING SICKNESS.} BX

\section{A. T. SCHOFIELD, M.R.C.S., L.R.C.P., C.M.S. Hospital, Toro, UGanda.}

Previous to July, 1924, the routine treatment of sleeping sickness in the C.M.S. Hospital, Toro, had been by atoxyl injections, with varying success. In July 50 grams of "Bayer 205" were sent by the principal medical officer and six cases were selected for comparative observation. Two were of the severe cerebral type, showing the later stages of the disease; two were of early cerebral type, with considerable glandular involvement; two were fairly early cases, with slight involvement of glands, etc. All came fron Katwe or the Semliki river area. In only one instance (severe cerebral type) had the patient received any previous treatment-namely, two injections of atoxyl three and four weeks before respectively, with only slight improvement. The blood contained trypanosomes in each patient except one early case, in whom the gland juices were positive.

One gram of "Bayer 205 " was, as advised by Kleine, given to adults intravenously, in $10 \mathrm{c.cm}$. physiological saline, on the first, third, fifth, twelfth, and seventeenth days. Routine cxaminations of the urine were made, but no albuminuria or other toxic signs, found by others, wero observed, and no ocular symptoms.

The blood examinations after the first injections were negative in every case. I fully appreciated the need of observation of the cerebro-spinal fluid, and only abandoned the attempt after very careful inquiry and consideration. The compound is a voluntary one, attached to a missionary hospital, and it mas thought that such a painful operation would be extromely likely to drive the patients away and keep others from coming, thus negativing the work of years.

The treatment was given in July and August, 1924, and in October and Norember all but the two severest cases were discharged at their own urgent request. Blood and gland examination in every case were then negative, and the patients had been completely free. from every sign or symptom of the disease for three months (the single possible exception is detailed below).

I persuaded the two "cerebral" cases to remain for longer observation, by promising gifts, etc. One had, in September, a slight return of drowsiness in the day time, but trypanosomes webe not found (he refused spinal puncture); I accordingly gave them both three further doses at weekly intervals. The history of these two cases is worth recording.

\section{Case 1.}

Juma, a man aged 28, when admitted on June 16th, was sleeping nearly all day; he was emaciated (weight $5 \mathrm{st} .13 \mathrm{lb}$.), incontinent, and there was coarse tremor of the tongue, etc.; glands mucl enlarged. Examination of the urine was negative. Trypanosomes enlarged. Examination of the urine was negative. Tryp
were present in the blcod. Temperature $99.2^{\circ}$, pulse 120.

An intravenous injection of atoxyl was given on June 17 th anci repeated on June 24 th. On June 30 th his weight had increased to $6 \mathrm{st}, 1 \mathrm{lb}$, and he was not sleeping so much. On July 15th ho was given 1'gram of "Bayer 205" intravenously. The foltowing day the temperature was $99.8^{\circ}$; no trypanosomes were found in the blood, and there was no albuminuria. He had not slept all day. The "Bayer 205" was repeated on July 17th, 19th, and 26th, and on August 12th. On August 11th his weight was 6 st. $11 \mathrm{ll}$., and on August 12th. On August 11th his weight was 6 st. $11 \mathrm{lb}$., he was able to answer questions. By September 4th the patient's weight had increased to $7 \mathrm{st} .4 \mathrm{lb}$.; he was reported to have been drowsy in the daytime during the last two days. He was given 1 gram of " 205 " on this dav, and again on Sieptember 11 given 18th. On October 7 th his weight was $7 \mathrm{st}$. $6 \mathrm{lb}$., and he was frce from symptoms; there was, however, some tremor, and the glands were still much enlarged.

\section{Case II.}

Everina, a girl aged 16, when admitted to hospital on July 2nd was sleeping nearly all day; she had been incontinent, and answered questions only after repeating three or four times. There was coarse tremor, and glands were very much enlarged; no ocular symptoms were present. Weight 4 st. $9 \mathrm{lb}$; t temperature $99.4^{\circ}$, pulse 116. Trypanosomes were found in the blood.

On' July 15 th 0.7 gram of "Baver 205 " was given intrarenouslr. there was no reaction; no albuminuria, etc. Temperature $99.6^{\circ}$; there was no reaction; no albuminuria, etc. Temperature $99 . \dot{6}^{\circ}$. during the day; no trypanosomes in the blood. On July $25 \mathrm{th}$ her weight was. 4 st. $12 \mathrm{lb}$; she was smiling and answered qucstions; tremor less; no trypanosomes. On August 11th she was quite bright; weight $5 \mathrm{st} .4 \mathrm{lb}$. On September 4 th she was given 0.7 gram of " Bayer 205," and again on September 11th and $181 \mathrm{l}$. By October 7th her weight had increased to $5 \mathrm{st} .6 \mathrm{lb}$; ; there were no symptoms, though there was still some tremor.

The later history of these two cases is very unfortunate, but interesting. It points to the necessity for prolonged observation and, if possible, examination of the cerebrospinal fluid.

On October 16th I went on Safari. Both patients were then apparently quite well and still gaining in weight. No symptoms had been observed. They had both wanted to return to their homes and it had taken considerable persuasion to induce them to remain. While I was away on Safari, on October 19th, both patients, apparently without any premonitory symptoms, went into the comatose final stage of the disease. They became incontinent and died within twenty-four hours. Such a rapid course is unusual in my own experience, and $I$ think might be considered hy a biologist for his explanation. The native attendants are quite emphatic in saying that there was no return of symptoms up to within a few hours of tho comatose stage, while I myself saw them four days before. It was unfortunate that I was away when this occurred. The blood had not been examined for two months.

The other four cases are reported to be still well after eight months (March, 1925).

\section{Summary.}

1. "Bayer $205 "$ is immensely superior to any ding previously tried.

2. It caused trypanosomes to disappear from the blood in twenty-four hours in the severest cases. 